\title{
BMJ Open Individual, parental and built environmental features as influencing factors of active travel to school in northeast China: findings from a cross- sectional study
}

Yinuo Wang (D) , ${ }^{1}$ Yang Liu, ${ }^{1}$ Shenzhi Song, ${ }^{1}$ Joel Gittelsohn, ${ }^{2}$ Miranda Ouellette, ${ }^{3}$ Yanan Ma, ${ }^{4}$ Deliang Wen (D) ${ }^{1}$

To cite: Wang Y, Liu Y, Song S, et al. Individual, parental and built environmental features as influencing factors of active travel to school in northeast China: findings from a crosssectional study. BMJ Open 2022;12:e047816. doi:10.1136/ bmjopen-2020-047816

- Prepublication history and additional supplemental material for this paper are available online. To view these files, please visit the journal online (http://dx.doi.org/10.1136/ bmjopen-2020-047816).

Received 10 December 2020 Accepted 24 September 2021

Check for updates

(c) Author(s) (or their employer(s)) 2022. Re-use permitted under CC BY-NC. No commercial re-use. See rights and permissions. Published by BMJ.

For numbered affiliations see end of article.

Correspondence to Professor Deliang Wen; dlwen@cmu.edu.cn

\section{ABSTRACT}

Objectives Active travel to school (ATS)-associated factors had been studied in some developed countries but rarely in China. We studied the associated factors of ATS at individual, parental and built environment domains in northeast China.

Design and participants A cross-sectional survey was conducted among 4-6 grade students in 2017. Sociodemographic features and information of parents were collected using questionnaires, and SuperMap (a geographical information system software) was used to catch built environment features. Logistic regression models were used to examine the relationship between multilevel factors and ATS.

Results Our study sample comprised 3670 primary school students aged from 8 to 15 (boys $=51.0 \%$, ATS $=48.8 \%)$. Perceived to be fat (OR $1.25,95 \% \mathrm{Cl} 1.00$ to $1.55, p<0.05)$, feeling easy to walk for a short distance (OR $1.63,95 \% \mathrm{Cl} 1.21$ to $2.20, \mathrm{p}<0.05)$, mother unemployed (OR 1.52, 95\% Cl 1.13 to 2.06, $\mathrm{p}<0.05$ ), higher land use mix (OR 1.23, 95\% Cl 1.11 to 1.37, $\mathrm{p}<0.001$ ) and higher density of public transport stations (OR 1.22, 95\% Cl 1.09 to $1.37, p<0.05$ ) were positively associated with increased possibility of ATS, while higher household annual income (OR $0.60,95 \% \mathrm{Cl} 0.44$ to $0.83, \mathrm{p}<0.05$ ) and possession of private vehicles (OR $0.56,95 \% \mathrm{Cl} 0.45$ to $0.69, \mathrm{p}<0.001$ ) were negatively associated with possibility of ATS. Conclusions The significant factors associated with ATS were at every examined level, which implies multilevel interventions are needed to encourage ATS. Further interventions could focus on the children's willingness to lead students to opt for healthy behaviours, and children from wealthier families should be encouraged to choose ATS. Also, the government should improve built environment walkability so as to encourage ATS.

\section{INTRODUCTION}

Higher levels of physical activity (PA) correlates positively with better physical and psychological health, ${ }^{1}$ which can protect children from cardiovascular diseases, obesity, metabolic syndrome and mental health
Strengths and limitations of this study

- Using geographical information system to get the objective features of the built environment.

- Combined objective and perceived features of the built environment.

- Study influencing factors of active travel to school from various domains.

- Short of evidence for cause and effect in crosssectional study.

- Lacking measurement of nature environment around household and parental accompanying neighbourhood safety.

problems later in life. ${ }^{2}$ WHO has recommended that children and adolescents aged 5-17 years engage in at least $60 \mathrm{~min}$ of moderate-to-vigorous PA daily. ${ }^{3}$ However, the number of Chinese children and adolescents who reach the WHO-recommended PA level has decreased since $1997 .{ }^{45}$ Data from a 2017 national survey showed that only $34.1 \%$ of children and adolescents met the $60 \mathrm{~min}$ recommended daily PA level. ${ }^{5}$

Active travel to school (ATS), a low-cost and sustainable health behaviour, is one of the ways to contribute to a higher level of PA. ${ }^{67}$ ATS is defined as walking, cycling and other forms of travelling to school (eg, skateboarding, in-line skating or crosscountry skiing) which consume energy. ${ }^{6}$ Although the evidence that ATS improves health is still mixed, ${ }^{89}$ some studies indicated that ATS was related to increased cardiorespiratory fitness ${ }^{10} 11$ and could lead to a healthier body composition and metabolic profile. ${ }^{12}$ One study noted that promoting and maintaining ATS could be a necessary component of a healthy lifestyle, 
and children engaging in ATS were more likely to be healthier in adulthood. ${ }^{13}$

Unfortunately, a worldwide decline in ATS has been observed. ${ }^{14}$ The prevalence of ATS among children aged 5-14 years old declined from $47.7 \%$ in 1969 to $12.7 \%$ in 2009 in the USA, ${ }^{15}$ and from $44.2 \%-57.7 \%$ in 1971 to $21.1 \%-25.5 \%$ during $1999-2003$ in Australia. ${ }^{16}$ Also, the proportion of children in Scotland walking, scooting or cycling to school has slightly decreased from $45.8 \%$ to $41.0 \%$ in the last 10 years. ${ }^{17} \mathrm{~A}$ study by Yang et $a l^{18}$ concluded that the percentage of children engaged in ATS markedly declined from $95.8 \%$ in 1997 to $69.3 \%$ in 2011 in China. As levels of ATS declined, it is important to identify factors associated with ATS in order to employ interventions to promote ATS.

Ecological models provide a comprehensive framework for promoting ATS in children. ${ }^{19}$ Sallis developed a multidomain model of active living with effects on each domain. ${ }^{19}$ Children's active behaviours are influenced at various levels by a range of individual, social, built environmental factors and so on. ${ }^{19-21}$ However, the influencing factors to be included in each domain are still being described. While some existing research suggests that child age and gender (individual domain) might relate to ATS, ${ }^{18} 22$ other work has reported no association. ${ }^{192} 24$ Most studies of the household domain have showed that with lower household income, lower parental education and lack of a private vehicle in the home, children were more likely to choose ATS. ${ }^{182526}$ At the level of the built environment (BE) domain, factors such as land use mix, residential density and intersection density, could influence the prevalence of ATS. ${ }^{27} 28$ Also, parents control their children's travelling behaviour to a great extent, ${ }^{28}$ and parents' perceived traffic-related and crime-related safety, play an important role in permitting and encouraging ATS. ${ }^{29} 30$

Few studies have comprehensively looked at the multiple domains of factors associated with ATS on the basis of ATS ecological models in China, and none have been conducted in Chinese mainland. A recent case study conducted in a primary school in Hong Kong reported ATS associated factors of sociodemographic and environment in neighbourhood. ${ }^{31}$ The authors pointed out that further studies might focus on multilevel contributors such as perceived neighbourhood safety and lifestyle attitude. ${ }^{31}$ In addition, in the studies aimed to explore the determinants of ATS among students in Beijing, they did not set up the models with relatively comprehensive influences, especially with a lack of perceptive environmental factors. ${ }^{20}{ }^{32}$ Thus, the aims of our study are to: (1) explore multilevel factors associated with ATS from individual, parental and BEs domains in a sampling of primary school students from Shenyang; and (2) explore the perceived traffic safety and crime safety issues of highest concern to parents in Shenyang and their association with ATS.

\section{METHODS}

\section{Study design}

Data were collected from students in fourth to sixth grade and their parents among 26 elementary schools in Shenyang City, China in 2017. Shenyang is the capital city of Liaoning province. The total area of Shenyang is 12942 $\mathrm{km}^{2}$ and consists of 13 administrative districts. By 2019, the number of permanent residents was 8.32 million.

Two schools from each of the 13 administrative districts of Shenyang were selected randomly and one class from each grade of each school was included. In China, students are assigned to classes randomly, which maximises the representativeness of the samples in this study. The questionnaires contained two parts: children's section and parental section, which were completed by children and parents separately (online supplemental file 1). In order to avoid children's misunderstanding of the questionnaires, all the words used in the children section were at grade levels 4-6. In addition, some assistants were trained by investigators so as they could explain to the children if they had some difficulties understanding questions in the children section of the questionnaire. Questionnaires were delivered to parents by their children and then taken back to school within 3 days. Trained survey assistants would examine the quality of the answers, and those uncompleted would be asked to answer again. And all of the children and their parents were invited to participate and could quit the study anytime. All the participants provided fully informed written consent.

\section{Measurements and variables definitions}

Active travel to school

For our study, ATS was measured with the children's questionnaire which asked, 'how do you usually travel to school?' Children who chose walking or riding a bicycle to school were categorised into the ATS group.

\section{Ecological model of ATS}

The influencing factors could be categorised into individual-level influences, household-level influences, surrounding BE influences in our study.

\section{Individual domain}

Information of age, gender and children's health attitudes was collected through the children's section in the questionnaires. Children were stratified into four groups according to the distribution of age $(\leq 9$, $10,11, \geq 12)$. Weight was measured using a portable Tanita DC-430MA dual frequency body composition monitor (TANITA Corporation, Tokyo, Japan) and standing height by a Seca 213 portable stadiometer (Hamburg, Germany). Body mass index (BMI) was calculated as weight $(\mathrm{kg})$ divided by height $(\mathrm{m})$ squared. Overweight/obesity was defined according to the cut-off BMI recommended by the Working Group on Obesity in China, as P85, based on data collection by the Chinese National Survey on Students Constitution and Health on students aged 7-18. The Physical 


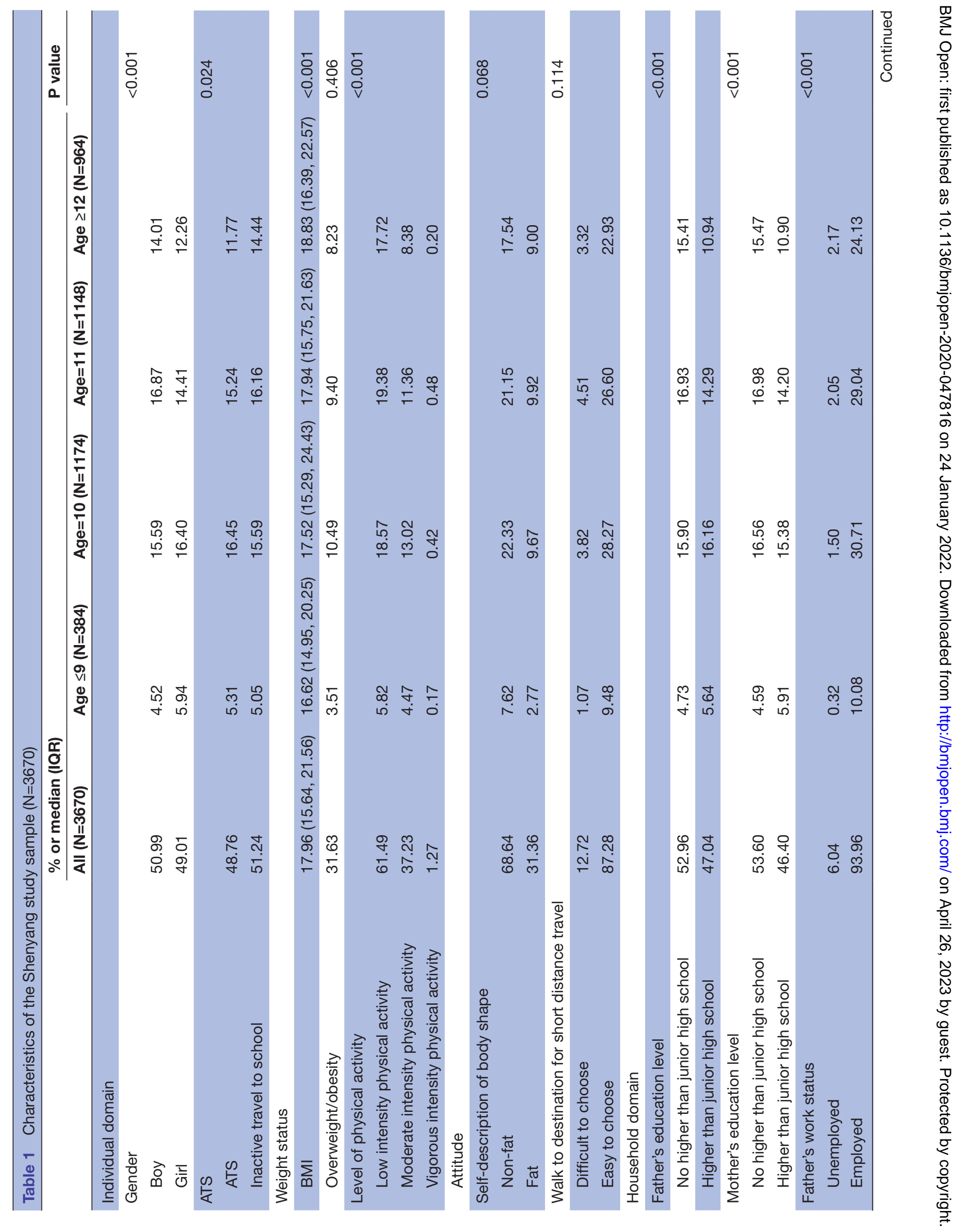




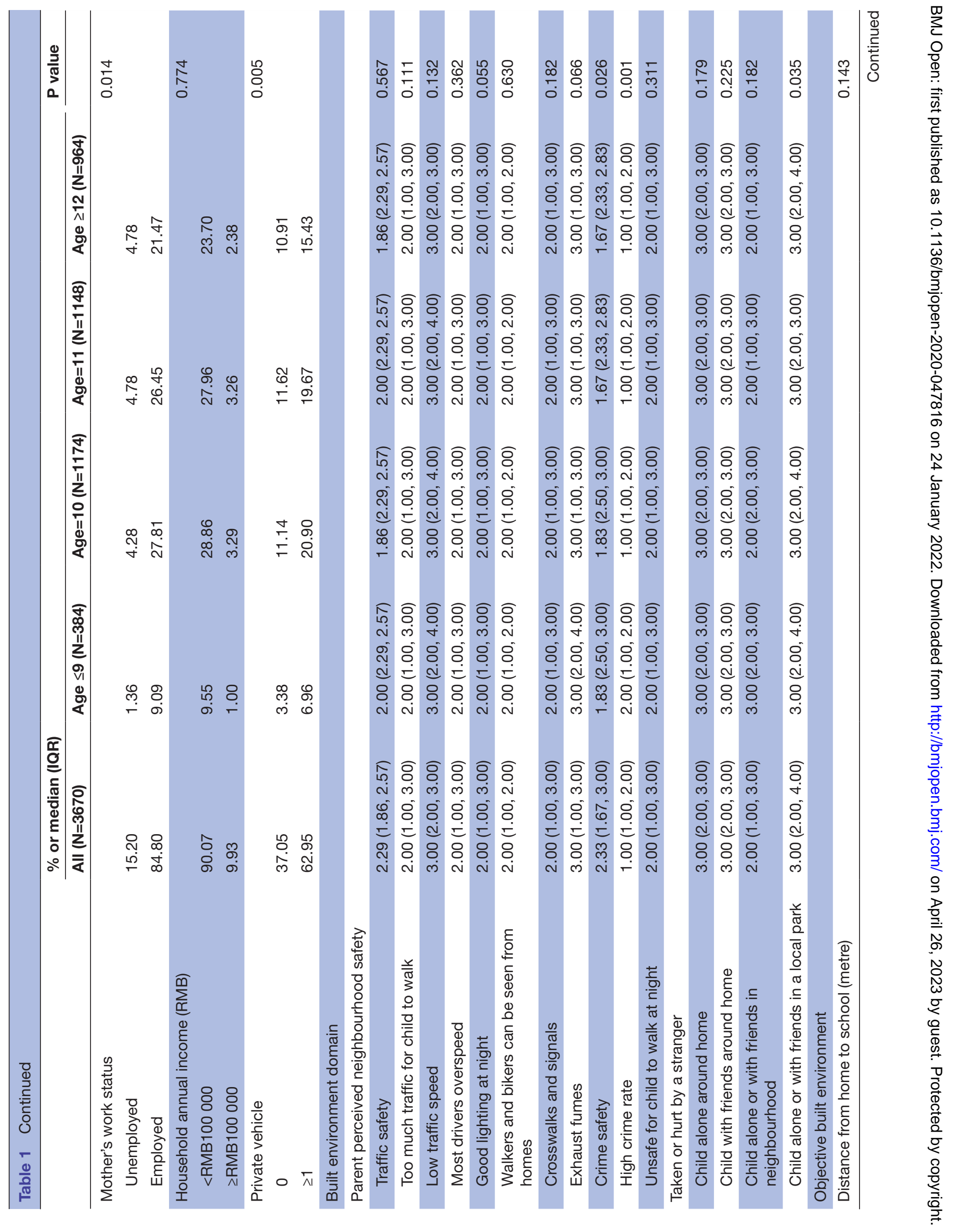


Activity Questionnaire for Children (PAQ-C) was used to estimate the children's PA level. The mean score of the items in PAQ-C is categorised into three different levels according to previous study: (1) >3.66, high; (2) 2.33-3.66, moderate; (3) <2.33, low. ${ }^{33}$ Children's selfperceptions were assessed through two questions: (1) please describe your body shape; (2) is it difficult for you to choose to walk to destination in short distance? Self-perception of body shape had five options, including pretty thin, a little bit thin, just, a little bit fat and pretty fat. Those that answered pretty thin, a little bit thin, just were classified as 'Non-fat self-perception' and others as 'Fat self-perception'. As for their attitude towards active commuting, it contained four options, including pretty difficult, difficult, easy and pretty easy. The children who answered 'pretty difficult' and 'difficult' were classified as 'Difficult to choose', and others as 'Easy to choose'.

\section{Household domain}

Information of the father's and mother's education degree and work status, as well as household annual income and possession of a private vehicle, was collected via parental section. Education degree was dichotomised based on whether parents had finished compulsory education, which includes 6 years of primary education and 3 years of junior secondary education (junior middle school). Parents' work status was divided into two categories, 'unemployed' and 'employed'. Household annual income was categorised as $\leq$ or $>$ RMB10 000 and possession of at least one private vehicle.

\section{Built environmental domain}

The detailed household addresses information was collected in the parent's section. Based on the accurate information of household address, the surrounding BE was measured by SuperMap geographical information system (GIS) 9D, a GIS software. Participants' household addresses were geocoded using their detailed address information gotten from questionnaire. Information on BE includes distances from household to school (collapsed by $1500 \mathrm{~m}$ into two categories consistent with parental reported approximate walking distance for children, ${ }^{34}$ residential density, land use mix, intersection density and density of public traffic stations around the household within a $1 \mathrm{~km}$ radius. The definitions of residential density, land use mix, intersection density and density of public traffic stations were shown in online supplemental file 2. A study found that residents with higher land use mix, residents from communities with higher density and greater connectivity reported higher rate of walking/ cycling. ${ }^{35}$ This finding on the importance of BE has also been supported for specific age groups, including youth. ${ }^{36-38}$ In addition, a recent system review indicated that public transportation had positive effects on PA behaviours. ${ }^{39}$ Therefore, we included residential density, land use mix, intersection density and density 
Table 2 Individual factors associated with ATS among 4-6 grade students from 26 primary schools in Shenyang ( $N=3670)$

\begin{tabular}{|c|c|c|c|c|}
\hline & \multicolumn{2}{|c|}{ Univariate model } & \multicolumn{2}{|c|}{ Multivariate model } \\
\hline & $P$ value & OR, $95 \% \mathrm{CI}$ & $P$ value & OR, $95 \% \mathrm{Cl}$ \\
\hline \multicolumn{5}{|l|}{ Age } \\
\hline$\geq 9$ & Ref & Ref & Ref & Ref \\
\hline 10 & 0.535 & 0.91 (0.68 to 1.22$)$ & 0.470 & 0.89 (0.66 to 1.21$)$ \\
\hline 11 & 0.400 & 1.14 (0.84 to 1.53$)$ & 0.331 & 1.16 (0.86 to 1.57$)$ \\
\hline$\geq 12$ & 0.033 & $1.40(1.03$ to 1.90$)$ & 0.052 & $1.36(1.00$ to 1.86$)$ \\
\hline \multicolumn{5}{|l|}{ Gender } \\
\hline Boy & Ref & Ref & - & - \\
\hline Girl & 0.197 & 0.90 (0.76 to 1.06$)$ & - & - \\
\hline \multicolumn{5}{|l|}{ Weight status } \\
\hline Normal & Ref & Ref & - & - \\
\hline Overweight and obesity & 0.482 & 1.07 (0.89 to 1.27$)$ & - & - \\
\hline \multicolumn{5}{|l|}{ Level of physical activity } \\
\hline Low intensity physical activity & Ref & Ref & - & - \\
\hline Moderate intensity physical activity & 0.105 & 0.87 (0.73 to 1.03$)$ & - & - \\
\hline Vigorous intensity physical activity & 0.551 & 0.78 (0.34 to 1.78$)$ & - & - \\
\hline \multicolumn{5}{|l|}{ Self-description of body shape } \\
\hline Non-fat & Ref & Ref & Ref & Ref \\
\hline Fat & 0.027 & 1.22 (1.02 to 1.47$)$ & 0.029 & $1.23(1.02$ to 1.47$)$ \\
\hline \multicolumn{5}{|l|}{ Walk to destination in short distance travel } \\
\hline Difficult to choose & Ref & Ref & Ref & Ref \\
\hline Easy to choose & $<0.001$ & $1.78(1.38$ to 2.30$)$ & $<0.001$ & $1.79(1.39$ to 2.32$)$ \\
\hline \multicolumn{5}{|l|}{ Distance from home to school (metre) } \\
\hline$<1500$ & Ref & Ref & Ref & Ref \\
\hline$\geq 1500$ & $<0.001$ & $0.13(0.11$ to 0.16$)$ & $<0.001$ & $0.13(0.11$ to 0.16$)$ \\
\hline
\end{tabular}

Adjusted by distance from household to school (1500m)

Results in bold indicate statistical significance at $p$-value $\leq 0.05$.

ATS, active travel to school.

of public traffic stations as indicators of BE in this ATS study. In addition, $\mathrm{z}$ score of residential density, land use mix, intersection density and density of public traffic stations was used for analysis.

Parents' perceived neighbourhood safety, including traffic safety and crime safety, was measured by neighbourhood safety subscales of Neighbourhood Environment Walkability Scale-Youth (NEWS-Y) Parent Version (Available on: https://drjimsallis.org/Documents/Measures_ documents/NEWS_Y_parent.pdf). The subscale of traffic safety contains seven questions and each question is measured on a 4-point Likert scale with options being (1) strongly disagree; (2) somewhat disagree; (3) somewhat agree and (4) strongly agree. Items 2 and 4-6 were reverse coded. A higher mean code of these seven items denotes lower traffic safety, which signifies parents think the traffic around their household is unsafe for their children. The crime safety subscale consists of six items which are valued in the same way. The higher mean code of these six items denotes lower crime safety, which signifies parents think the environment around their household is unsafe for their child because of crime.

\section{Statistical analysis}

STATA V.14.0 was used to analyse the data. First, $\chi^{2}$ test and non-parametric Kruskal-Wallis test were used to identify significant differences between age groups for categorical variables and continuous variables separately. Logistic regression model was used to examine the relationship between multilevel factors and ATS. The regression modelling controlled the distance from household to school, because it has been proved to be strongly associated with ATS in previous studies, ${ }^{40}$ (online supplemental file 3), included three steps. First, each individual, parental and built environmental factor, together with distance from household to school, was examined regarding its relationship with ATS one at a time (univariate test) and was used to create a series of univariate models. Second, all significant individual variables from the univariate model and distance from household to school were added together to generate 
Table 3 Household factors associated with ATS among 4-6 grade students from 26 primary schools in Shenyang

\begin{tabular}{|c|c|c|c|c|}
\hline & \multicolumn{2}{|c|}{ Univariate model } & \multicolumn{2}{|c|}{ Multivariate model } \\
\hline & $P$ value & OR, $95 \% \mathrm{Cl}$ & $P$ value & OR, $95 \% \mathrm{Cl}$ \\
\hline \multicolumn{5}{|l|}{ Father's education level } \\
\hline No higher than junior high school & Ref & Ref & - & - \\
\hline Higher than junior high school & 0.653 & 0.96 (0.81 to 1.14$)$ & - & - \\
\hline \multicolumn{5}{|l|}{ Mother's education level } \\
\hline No higher than junior high school & Ref & Ref & - & - \\
\hline Higher than junior high school & 0.581 & 0.95 (0.80 to 1.12$)$ & - & - \\
\hline \multicolumn{5}{|l|}{ Father's work status } \\
\hline Unemployed & Ref & Ref & - & - \\
\hline Employed & 0.521 & 0.88 (0.59 to 1.31$)$ & - & - \\
\hline \multicolumn{5}{|l|}{ Mother's work status } \\
\hline Unemployed & Ref & Ref & Ref & Ref \\
\hline Employed & 0.027 & 1.32 (1.03to 1.68) & 0.019 & 1.37 (1.05 to 1.79$)$ \\
\hline \multicolumn{5}{|l|}{ Household annual income (RMB) } \\
\hline$<$ RMB100 000 & Ref & Ref & Ref & Ref \\
\hline$\geq$ RMB100 000 & 0.001 & 0.62 (0.47to 0.83 ) & 0.041 & 0.73 (0.55to 0.99$)$ \\
\hline \multicolumn{5}{|l|}{ Private vehicle } \\
\hline 0 & Ref & Ref & Ref & Ref \\
\hline$\geq 1$ & $<0.001$ & 0.54 (0.45to 0.64) & $<0.001$ & 0.56 (0.46to 0.68$)$ \\
\hline \multicolumn{5}{|l|}{ Distance from home to school (metre) } \\
\hline$<1500$ & Ref & Ref & Ref & Ref \\
\hline$\geq 1500$ & $<0.001$ & 0.13 (0.11to 0.16$)$ & $<0.001$ & $0.13(0.11$ to 0.16$)$ \\
\hline
\end{tabular}

Adjusted by distance from household to school (1500m)

Results in bold indicate statistical significance at $p$-value $\leq 0.05$.

ATS, active travel to school.

the individual multivariate model. The same processes were implied to generate the parental multivariate model and BE multivariate model. Finally, all significant variables from the individual multivariate model, parental multivariate model and BE multivariate model were used to generate a multilevel model. Significance was set at the 0.05 level.

\section{Patient and public involvement}

No patients were involved in setting the research question or the outcome measures, nor involved in the design, implementation of the study, reporting or dissemination plans of our research. Also, the public did not participate in the design, implementation of the study, reporting or dissemination plans of our research.

\section{RESULTS}

Table 1 provides an overview of the descriptive statistics for children, parental and BE characteristics. At first, 3863 students from grade 4 to grade 6 were included. After quality examination, 3670 children (aged $8-15$ years old) completed questionnaires in total, and $51.0 \%$ of the subjects were boys. $48.8 \%$ of the children reported walking or riding a bicycle to school. The median of BMI was
17.96, with an overall prevalence of overweight/obesity being $31.6 \%$, defined by BMI. The rates of children who reached moderate intensity $\mathrm{PA}$ and vigorous intensity $\mathrm{PA}$ were $37.2 \%$ and $1.3 \% .66 .8 \%$ of the children thought they were 'Not fat', and it was easy for $87.3 \%$ of the students to walk to their destination over a short distance.

The majority of fathers and mothers had a junior high school education or less, $52.9 \%$ and $53.6 \%$, respectively. Only $6.0 \%$ fathers and $15.2 \%$ mothers were unemployed, and $9.9 \%$ of families earned more than RMB100 000 a year, while $63.0 \%$ had at least one private vehicle.

The perceived parental neighbourhood safety questions consisted of traffic safety and crime safety, with 2.29 and 2.33 as median of traffic safety score and crime safety score. Within subscale of neighbourhood safety, 'Slow traffic speed' and 'Child alone or with friends in a local park taken or hurt by a stranger' were of most concern, with a median of 3.00 both. Distance from home to school was divided by $1500 \mathrm{~m}$, with the prevalence being $61.5 \%$ less than $1500 \mathrm{~m}$ and $38.6 \%$ more than $1500 \mathrm{~m}$. The median of residential density, land use mix, intersection density and public transport stations was 7.97, 142.00, 13.00 and 1.33 , respectively. 
Age disparities were found in some aspects, including gender, ATS, BMI, level of PAs, parent's degree, parent's work status, possession of private vehicle, good lighting at night, high crime rate, child being taken or hurt by a stranger in local or nearby park, residential density and land use mix. There were more boys than girls under 10 years old and more girls in the group older than 11 years old. The prevalence of ATS and BMI increased with age. And level of PA decreased along with the growth. The younger children had better socioeconomic status because of parental higher education with job and possession of private cars. And younger children's parents perceived neighbourhood crime safety worse than the older group. Also, younger group had a higher score of residential density and land use mix around their households.

\section{Associations with ATS by level}

As shown in table 2, older children ( $\geq 12$ years old) were more likely to choose ATS. If the children thought they were fat (OR $1.23,95 \%$ CI 1.02 to 1.47 , $\mathrm{p}<0.05)$ or it was easy for them to walk for short distance (OR $1.79,95 \%$ CI 1.38 to $2.03, \mathrm{p}<0.001$ ), they were more likely to choose ATS. Interestingly, there were no apparent differences in ATS between boys and girls, or by different levels of PA. Also, the difference in ATS between normal weight status and overweight or obesity was insignificant. After all significant individual variables were included in one multivariate model, those perceived to be fat and felt easy to choose to walk for short distance remained to associate with increased ATS.

At the household level, having an unemployed mother $(\mathrm{OR}=1.37, \mathrm{p}<0.05)$, higher household annual income (OR $0.73,95 \%$ CI 0.55 to $0.99, \mathrm{p}<0.05$ ) and at least one private vehicle (OR $0.56,95 \%$ CI 0.46 to 0.68 , $\mathrm{p}<0.001$ ) was associated with less ATS (table 3). These findings remained significant in the combined household model.

At the BE domain in table 4, residential density-z score (OR 1.17, 95\% CI 1.08 to 1.27, $\mathrm{p}<0.001$ ), land use-z score (OR $1.28,95 \%$ CI 1.17 to $1.40, \mathrm{p}<0.001$ ), intersection density-z score (OR 1.20, 95\% CI 1.11 to $1.30, \mathrm{p}<0.001$ ), public transport stations density-z score (OR 1.17, 95\% CI 1.07 to $1.29, \mathrm{p}<0.05)$ and crime safety (OR $0.89,95 \%$ CI 0.80 to $0.99, \mathrm{p}<0.05$ ) were all associated with increased child ATS. In the multivariate model, land use-z score (OR $1.22,95 \%$ CI 1.11 to $1.35, \mathrm{p}<0.05)$ and public transport stations-z score (OR 1.16 (1.05 to 1.28$), \mathrm{p}<0.05$ ) were significantly associated with increased ATS. The safety issue that parents are most concerned about was: 'I am worried about letting my child be alone or with friends in a local or nearby park because I am afraid my child will be taken or hurt by a stranger (online supplemental file 4).

\section{DISCUSSION}

This was the first study to gather information concerning ATS among children in China, and compared associations with factors at the individual, parental and built environmental domains. Children perceived to be fat and felt it was easy to walk for a short distance, mother unemployed, higher land use mix and higher density of public transport stations increased ATS, while higher household annual income and possession of private vehicles decreased the possibility of ATS.

\section{Individual domain}

Consistent with other studies, primary school students older than 12 years old were more likely to actively travel to school than their younger counterparts. ${ }^{1842}$ This may be because only those older than 12 years old are allowed to

Table 4 Built environment factors associated with ats among 4-6 grade students from 26 primary schools in Shenyang

\begin{tabular}{|c|c|c|c|c|}
\hline & \multicolumn{2}{|c|}{ Univariate model } & \multicolumn{2}{|c|}{ Multivariate model } \\
\hline & $P$ value & OR, $95 \% \mathrm{Cl}$ & $P$ value & OR, $95 \% \mathrm{Cl}$ \\
\hline Residential density (Z score) & $<0.001$ & 1.17 (1.08 to 1.27$)$ & 0.182 & 1.08 (0.96to 1.21$)$ \\
\hline Land use mix (Z score) & $<0.001$ & $1.28(1.17$ to 1.40$)$ & $<0.001$ & 1.22 (1.11to 1.35$)$ \\
\hline intersection density (Z score) & $<0.001$ & 1.20 (1.11 to 1.30$)$ & 0.183 & 1.07 (0.97to 1.18$)$ \\
\hline Density of public transport stations (Z score) & 0.001 & $1.17(1.07$ to 1.29$)$ & 0.005 & 1.16 (1.05to 1.28) \\
\hline Traffic safety & 0.766 & 0.97 (0.81 to 1.17$)$ & - & - \\
\hline Crime safety & 0.039 & 0.89 (0.80 to 0.99$)$ & 0.152 & 0.91 (0.81 to 1.03$)$ \\
\hline \multicolumn{5}{|l|}{ Distance from home to school (metre) } \\
\hline$<1500$ & Ref & Ref & Ref & Ref \\
\hline$\geq 1500$ & $<0.001$ & 0.13 (0.11 to 0.16$)$ & $<0.001$ & $0.16(0.13$ to 0.20$)$ \\
\hline
\end{tabular}

Multilevel associations with ATS.

The multivariate model was generated by combining the individual model, parental model and built environment model, retaining only significant variables. All variables at all levels remained statistically significant with ATS in this model (table 5).

Adjusted by distance from household to school (1500m)

Results in bold indicate statistical significance at $p$-value $\leq 0.05$.

ATS, active travel to school. 
Table 5. Combined multilevel analysis of individual, parental and built environment and their association with ATS

\begin{tabular}{|c|c|c|}
\hline & $P$ value & OR, $95 \% \mathrm{Cl}$ \\
\hline \multicolumn{3}{|l|}{ Self-description of body shape } \\
\hline Non-fat & Ref & Ref \\
\hline Fat & 0.046 & 1.25 (1.00 to 1.55$)$ \\
\hline \multicolumn{3}{|c|}{ Walk to destination in short distance travel } \\
\hline Difficult to choose & Ref & Ref \\
\hline Easy to choose & 0.001 & $1.63(1.21$ to 2.20$)$ \\
\hline \multicolumn{3}{|l|}{ Mother's work status } \\
\hline Unemployed & Ref & Ref \\
\hline Employed & 0.006 & 1.52 (1.13to 2.06) \\
\hline \multicolumn{3}{|c|}{ Household annual income (RMB) } \\
\hline$<$ RMB100 000 & Ref & Ref \\
\hline$\geq$ RMB100 000 & 0.002 & 0.60 (0.44to 0.83$)$ \\
\hline \multicolumn{3}{|l|}{ Private vehicle } \\
\hline 0 & Ref & Ref \\
\hline$\geq 1$ & $<0.001$ & 0.56 (0.45to 0.69$)$ \\
\hline Land use mix (Z score) & $<0.001$ & 1.23 (1.11to 1.37) \\
\hline $\begin{array}{l}\text { Density of public transport } \\
\text { stations ( } Z \text { score) }\end{array}$ & $<0.001$ & 1.22 (1.09to 1.37) \\
\hline \multicolumn{3}{|c|}{ Distance from home to school (metre) } \\
\hline$<1500$ & Ref & Ref \\
\hline$\geq 1500$ & $<0.001$ & 0.17 (0.13to 0.21$)$ \\
\hline
\end{tabular}

Adjusted by distance from household to school (1500m)

Results in bold indicate statistical significance at $p$-value $\leq 0.05$. ATS, active travel to school.

ride a bicycle on the road according to traffic regulations of China. There was no difference between gender in ATS, which was consistent with previous studies of China and $\mathrm{UK}^{1843}$ and inconsistent with some USA studies. ${ }^{445}$ As for the gender difference, it was proved that boys were more likely to travel to school actively in some USA studies. ${ }^{445}$ In addition, caregivers' preference of active commuting and their familiarity of the environment around household might change the gender influence on the choice of active mode to school. ${ }^{45}$ On the other hand, a research might provide potential explanation, which pointed out that girls preferred to walk to and from school, however, boys preferred to cycle to and from school. ${ }^{46}$ Therefore, girls and boys might prefer different types of ATS, while there was no gender difference on overall ATS preference in China. An existing study reported children who were dissatisfied with their body shape were less likely to be satisfied with their level of PAs, ${ }^{47}$ which agreed with our findings indicating that perception of self-body image as overweight was positively related to preference of ATS. It might be explained that children who were not satisfied with their body shape are more willing to be more active to lose weight. As for those who felt easy to choose to walk to destination in short distance, it is not a surprise to see that they preferred to take active mode to school since students studied in public school will be arranged to the school nearby their households. To further motivate ATS, health education related to self-perception of body shape and health preference should be made and taught to primary school students. By doing this, students would potentially be more willing to take part in ATS, especially those who are not satisfied with their current body shape.

\section{Household domain}

We found that household factors played an important role in determining their children's mode of travelling to school. ${ }^{48}$ Generally, higher level household annual income and vehicle ownership were negatively related to ATS, in accordance with existing studies. ${ }^{18} 25$ Also, maternal employment was positively related to ATS. This finding was inconsistent with the previous studies indicating that working mothers were more likely to drive their children to school (compared with non-workers). ${ }^{49}$ A possible reason might be that mothers, as the principal caregiver mostly in China, who were employed might have a busier schedule than those unemployed so that they could not drive their children to school.

\section{Built environment domain}

Our findings about the built environment are confirmed by other studies about the role of built environmental factors such as land use mix. ${ }^{27} 2842$ With the use of GIS and NEWS-Y-Parent Version, both objective and subjective features, including residential density, land use mix, intersection density, density of public transportation stations and parents' perceived traffic safety as well as crime safety, were examined and some modifiable features were associated with ATS. Land use mix-z score was significantly related to preference of ATS, which was similar to previous studies. ${ }^{27} 2842$ Interestingly, density of public transportation stations-z score was found to be a positive factor of ATS which was a novelty compared with previous study. However, residential density and intersection density which were indicated as associated factors of ATS in previous study were not significant in our study. ${ }^{2150}$ It might be because the traffic around households with plenty of public transportation stations was busier and people were more likely to walk/ride for short distances. Parent-perceived neighbourhood safety was also a part of built environment and in some non-China studies, the neighbourhood parents perceived to be unsafe would decrease the prevalence of ATS. ${ }^{29} 3051$ However, the parents' perceived neighbourhood safety was not related to ATS in our study. Among all the traffic safety items and crime safety items, 'Low traffic speed' and 'Child alone or with friends in a local or nearby park taken or hurt by a stranger' were of highest concern to parents. The latter one was showed to be related to inactive travel to school. In a previous US study, ${ }^{52}$ the average scores of traffic safety and crime safety were much higher than that in our study. And another Mexico study showed the 'good lighting 
at night' and 'high crime rate' were most of parents' concern.$^{53}$ Hence, parents from different countries might concern about different types of neighbourhood safety, however, compared with USA, Chinese parents might feel safer about the traffic and crime safety around their household, which might help enhance children's ATS. The NEWS-Y might not be suitable for Chinese society and studies could focus on the development of a Chinese version of the NEWS-Y in the future. Also, some questions about crime safety are related to friends accompanying, however, parental accompanying mode was not assessed.

Our study indicated that children's description of their own body shape and healthy choice to walk for short distances were positively related to ATS. A study conducted among adolescents indicated that body shape perception was strongly related to PAs,${ }^{54}$ which is accordance with our study. In addition, the results of a previous study suggested that concerning body shape would benefit motor performance among juveniles. ${ }^{55}$ So further intervention could focus on the children's willingness to lead students to opt for healthy behaviours. The related parental factors indicated children from wealthier families were more likely to take an inactive mode to school. Thus, children from wealthier families should be encouraged to choose ATS. As for built environmental features affecting ATS, the government should improve the land use mix so as to encourage ATS. Additionally, increasing perceived safety could help with the promotion of ATS to some extent. The significant factors associated with ATS were at every examined level, which implies multilevel interventions are needed to encourage ATS.

Our research conducted among primary school students in Shenyang showed significant associations between factors at multiple levels and ATS. Given the findings of our study, health education for families may help increase the prevalence of ATS, and wealthier household children should receive targeted interventions to promote ATS. Furthermore, providing a pedestrian-friendly built environment (such as more land use mix and better neighbourhood safety) may increase ATS. Therefore, further interventions should be targeted on health education and modifiable built environment features to increase ATS.

This study was not without limitations. First, the study was a cross-sectional study which could not analyse causality. Second, sampling regarding the natural environmental features around households in Shenyang primary school students is still needed to be studied its association with ATS. Further cohort studies with large samplings from different areas of China may help to study the relationship between ATS and its related factors and could help examine its differences among regions in China. Third, only independent and friend-accompanying mode of neighbourhood safety were measured in the NEWS-Y, however, parental accompanying neighbourhood safety is also a crucial part needed to be concerned in further research. There are also some strengths of this study. We studied various factors associated with ATS from an individual, parental and built environmental domains. Also, we first used GIS and NEWS-Y to measure the objective built environment characters and parents' perceived neighbourhood safety separately so as to study built environmental factors associated with ATS.

\section{Author affiliations}

${ }^{1}$ Institute of Health Science, China Medical University, Shenyang, Liaoning, China ${ }^{2}$ Center for Human Nutrition, Department of International Health, Johns Hopkins University Bloomberg School of Public Health, Baltimore, Maryland, USA

${ }^{3}$ Johns Hopkins University Bloomberg School of Public Health, Baltimore, Maryland, USA

${ }^{4}$ Biostatistics and Epidemiology, China Medical University Department of Social Sciences, Shenyang, Liaoning, China

Contributors YW: formal analysis, data curation, writing-original draft preparation; YL: conceptualisation, methodology, investigation; SS: investigation; JG: writingreviewing and editing, methodology; MO: writing-reviewing and editing; Y-NM: conceptualisation; DW: supervision; guarantor.

Funding This work was supported by the Chinses National Natural Science Foundation.

Competing interests None declared.

Patient consent for publication Not applicable.

Ethics approval This study was ethically approved by the Medical Ethics Committee of China Medical University, China (ref no: 71774173).

Provenance and peer review Not commissioned; externally peer reviewed.

Data availability statement Data are available on reasonable request. Data are available upon reasonable request. And please email to corresponding author: Professor Deliang Wen. Email address: dlwen@cmu.edu.cn.

Supplemental material This content has been supplied by the author(s). It has not been vetted by BMJ Publishing Group Limited (BMJ) and may not have been peer-reviewed. Any opinions or recommendations discussed are solely those of the author(s) and are not endorsed by BMJ. BMJ disclaims all liability and responsibility arising from any reliance placed on the content. Where the content includes any translated material, BMJ does not warrant the accuracy and reliability of the translations (including but not limited to local regulations, clinical guidelines, terminology, drug names and drug dosages), and is not responsible for any error and/or omissions arising from translation and adaptation or otherwise.

Open access This is an open access article distributed in accordance with the Creative Commons Attribution Non Commercial (CC BY-NC 4.0) license, which permits others to distribute, remix, adapt, build upon this work non-commercially, and license their derivative works on different terms, provided the original work is properly cited, appropriate credit is given, any changes made indicated, and the use is non-commercial. See: http://creativecommons.org/licenses/by-nc/4.0/.

\section{ORCID iDs}

Yinuo Wang http://orcid.org/0000-0003-3037-5340

Deliang Wen http://orcid.org/0000-0002-4038-3849

\section{REFERENCES}

1 Rhodes RE, Janssen I, Bredin SSD, Hansen RK, Larsen RG, Laessoe $\mathrm{U}$, et al. Physical activity: health impact, prevalence, correlates and interventions. Psychol Health 2017;32:942-75.

2 Ekelund U, Luan Jian'an, Sherar LB, et al. Moderate to vigorous physical activity and sedentary time and cardiometabolic risk factors in children and adolescents. JAMA 2012;307:704-12.

3 WHO. Global recommendations on physical activity for health. 978-92-4-159-997-9. Geneva: WHO, 2010.

4 Li F, Mao L, Chen P. Physical activity and prevention of chronic disease in Chinese youth: a public health approach. J Sport Health Sci 2019;8:512-5.

5 Lu C, Shen T, Huang G, et al. Environmental correlates of sedentary behaviors and physical activity in Chinese preschool children: a cross-sectional study. J Sport Health Sci 2020. doi:10.1016/j. jshs.2020.02.010. [Epub ahead of print: 28 Apr 2020].

6 Palma CN, Sandra M. Active transport to and from school. In advances in transportation and health. Amsterdam, The Netherlands: Elsevier, 2020. 
7 Peralta M, Henriques-Neto D, Bordado J, et al. Active Commuting to school and physical activity levels among 11 to 16 year-old adolescents from 63 low- and middle-income countries. Int J Environ Res Public Health 2020;17:1276.

8 Mendoza JA, Liu Y. Active commuting to elementary school and adiposity: an observational study. Child Obes 2014;10:34-41.

9 Saunders LE, Green JM, Petticrew MP, et al. What are the health benefits of active travel? A systematic review of trials and cohort studies. PLoS One 2013;8:e69912.

10 Larouche R, Saunders TJ, Faulkner GEJ, et al. Associations between active school transport and physical activity, body composition, and cardiovascular fitness: a systematic review of 68 studies. J Phys Act Health 2014;11:206-27.

11 Børrestad LAB, Ostergaard L, Andersen LB, et al. Experiences from a randomised, controlled trial on cycling to school: does cycling increase cardiorespiratory fitness? Scand J Public Health 2012;40:245-52.

12 Pizarro AN, Ribeiro JC, Marques EA, et al. Is walking to school associated with improved metabolic health? Int J Behav Nutr Phys Act 2013;10:12.

13 Yang $X$, Telama R, Hirvensalo M, et al. Active commuting from youth to adulthood and as a predictor of physical activity in early midlife: the young Finns study. Prev Med 2014;59:5-11.

14 Yang Y, Xue H, Liu S, et al. Is the decline of active travel to school unavoidable by-products of economic growth and urbanization in developing countries? Sustain Cities Soc 2019;47:101446.

15 McDonald NC, Brown AL, Marchetti LM, et al. U.S. school travel, 2009 an assessment of trends. Am J Prev Med 2011;41:146-51.

16 van der Ploeg HP, Merom D, Corpuz G, et al. Trends in Australian children traveling to school 1971-2003: burning petrol or carbohydrates? Prev Med 2008;46:60-2.

17 Pearce M, Ryan A, Joy CA. Travel to School in Scotland, hands up scotland survey 2019: National summary report. Transport Scotland; 2019

18 Yang $\mathrm{Y}$, Hong $\mathrm{X}$, Gurney JG. Active travel to and from school among school-age children during 1997-2011 and associated factors in China. Am J Health Behav 2017;14:684-91.

19 Sallis JF, Cervero RB, Ascher W, et al. An ecological approach to creating active living communities. Annu Rev Public Health 2006;27:297-322.

$20 \mathrm{Li} \mathrm{S}$, Zhao P. The determinants of commuting mode choice among school children in Beijing. Journal of Transport Geography 2015;46:112-21.

21 Carlson JA, Sallis JF, Kerr J, et al. Built environment characteristics and parent active transportation are associated with active travel to school in youth age 12-15. Br J Sports Med 2014;48:1634-9.

22 Villa-González E, Ruiz JR, Mendoza JA, et al. Effects of a schoolbased intervention on active commuting to school and health-related fitness. BMC Public Health 2017;17:20.

23 Mammen G, Stone MR, Faulkner G, et al. Active school travel: an evaluation of the Canadian school travel planning intervention. Prev Med 2014;60:55-9.

24 Timperio A, Ball K, Salmon J, et al. Personal, family, social, and environmental correlates of active commuting to school. Am J Prev Med 2006;30:45-51.

25 Rothman L, Macpherson AK, Ross T, et al. The decline in active school transportation (AST): a systematic review of the factors related to AST and changes in school transport over time in North America. Prev Med 2018;111:314-22.

26 Carlson JA, Mignano AM, Norman GJ, et al. Socioeconomic disparities in elementary school practices and children's physical activity during school. Am J Health Promot 2014;28:S47-53.

27 Carlson JA, Sallis JF, Kerr J, et al. Built environment characteristics and parent active transportation are associated with active travel to school in youth age 12-15. Br J Sports Med 2014;48:1634-9.

28 De Meester F, Van Dyck D, De Bourdeaudhuij I, et al. Parental perceived neighborhood attributes: associations with active transport and physical activity among 10-12 year old children and the mediating role of independent mobility. BMC Public Health 2014; $14: 631$

29 Yu C-Y, Zhu X. From attitude to action: what shapes attitude toward walking to/from school and how does it influence actual behaviors? Prev Med 2016;90:72-8

30 Oluyomi AO, Lee C, Nehme E, et al. Parental safety concerns and active school commute: correlates across multiple domains in the home-to-school journey. Int J Behav Nutr Phys Act 2014;11:32.

31 Leung KYK, Loo BPY. Determinants of children's active travel to school: a case study in Hong Kong. Travel Behaviour and Society 2020;21:79-89.
32 Zhang R, Yao E, Liu Z. School travel mode choice in Beijing, China. Journal of Transport Geography 2017;62:98-110.

33 Su TT, Sim PY, Nahar AM, et al. Association between self-reported physical activity and indicators of body composition in Malaysian adolescents. Prev Med 2014;67:100-5.

34 Timperio A, Crawford D, Telford A, et al. Perceptions about the local neighborhood and walking and cycling among children. Prev Med 2004;38:39-47.

35 Saelens BE, Sallis JF, Frank LD. Environmental correlates of walking and cycling: findings from the transportation, urban design, and planning literatures. Ann Behav Med 2003;25:80-91.

36 Davison K, Lawson CT. Do attributes in the physical environment influence children's physical activity? A review of the literature. International Journal of Behavioral Nutrition and Physical Activity 2006;3:19-36.

37 Rosso AL, Auchincloss AH, Michael YL. The urban built environment and mobility in older adults: a comprehensive review. J Aging Res 2011;2011:1-10.

38 Saelens BE, Papadopoulos C. The importance of the built environment in older adults' physical activity: A review of the literature. Washington State Journal of Public Health Practice 2008;1:13-21.

39 Tcymbal A, Demetriou Y, Kelso A, et al. Effects of the built environment on physical activity: a systematic review of longitudinal studies taking sex/gender into account. Environ Health Prev Med 2020;25:75.

40 Trapp GSA, Giles-Corti B, Christian HE, et al. Increasing children's physical activity: individual, social, and environmental factors associated with walking to and from school. Health Educ Behav 2012;39:172-82.

41 Panter J, Corder K, Griffin SJ, et al. Individual, socio-cultural and environmental predictors of uptake and maintenance of active commuting in children: longitudinal results from the speedy study. Int $J$ Behav Nutr Phys Act 2013;10:83.

42 Martin SL, Lee SM, Lowry R. National prevalence and correlates of walking and bicycling to school. Am J Prev Med 2007;33:98-105.

43 Metcalf B, Voss L, Jeffery A, et al. Physical activity cost of the schoo run: impact on schoolchildren of being driven to school (EarlyBird 22). BMJ 2004;329:832-3.

44 McDonald NC. Is there a gender gap in school travel? an examination of US children and adolescents. Journal of Transport Geography 2012;20:80-6.

45 Marlon GB, Tracy M, Kristen D. Johnny Walks to School-Does Jane? Sex Differences in Children's Active Travel to School. Children Youth and Environments 2006;16.

46 Leslie E, Kremer P, Toumbourou JW, et al. Gender differences in personal, social and environmental influences on active travel to and from school for Australian adolescents. J Sci Med Sport 2010;13:597-601.

47 Min J, Yan AF, Wang VHC, et al. Obesity, body image, and its impact on children's eating and exercise behaviors in China: a nationwide longitudinal study. Prev Med 2018;106:101-6.

48 Kerr J, Rosenberg D, Sallis JF, et al. Active commuting to school: associations with environment and parental concerns. Med Sci Sports Exerc 2006;38:787-94.

49 Yarlagadda AK, Srinivasan S. Modeling children's school travel mode and parental escort decisions. Transportation 2008;35:201-18.

50 Jia $\mathrm{P}$, Xue H, Cheng X, et al. Association of neighborhood built environments with childhood obesity: evidence from a 9-year longitudinal, nationally representative survey in the US. Environ Int 2019;128:158-64.

51 Kim YJ, Lee C. Built and Natural Environmental correlates of parental safety concerns for children's active travel to school. Journal of Physical Activity and Health 2020;17:517.

52 Datar A, Nicosia N, Wong E, et al. Neighborhood environment and children's physical activity and body mass index: evidence from military personnel installation assignments. Child Obes 2015;11:130-8.

53 Hermosillo-Gallardo ME, Sebire SJ, Jago R. Perception of safety and its association with physical activity in adolescents in Mexico. Am J Prev Med 2020;58:748-55.

54 Miranda VP, Amorim PRS, Bastos RR, et al. Body image disorders associated with lifestyle and body composition of female adolescents. Public Health Nutr 2021;24:95-105.

55 Giuriato M, Kawczynski A, Mroczek D, et al. Allometric association between physical fitness test results, body size/shape, biological maturity, and time spent playing sports in adolescents. PLoS One 2021;16:e0249626. 